\title{
Evaluation of the effects of water quality on drinking preferences of heifer calves
}

\author{
N. D. Senevirathne, ${ }^{1} \oplus$ J. L. Anderson, ${ }^{1} \odot$ P. S. Erickson, ${ }^{2} \odot$ and M. Rovai ${ }^{1 *} \odot$
}

\section{Graphical Abstract}

TYPES OF DRINKING WATER

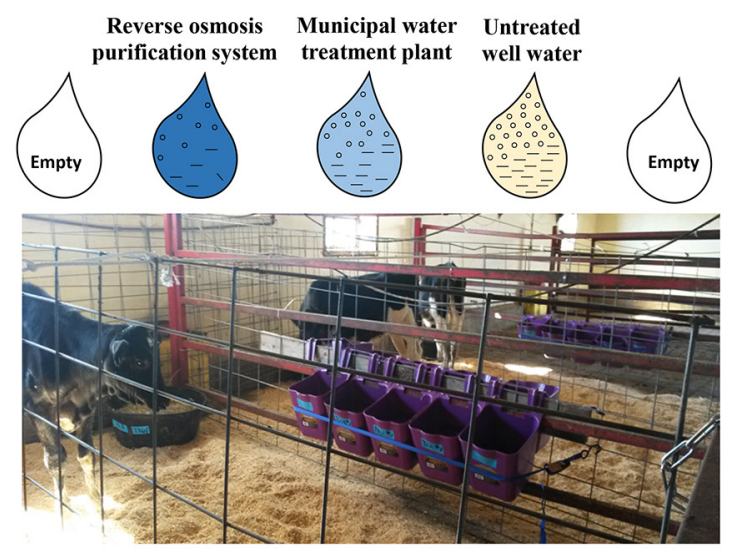

WATER TYPE OF CHOICE:
reverse osmosis water system

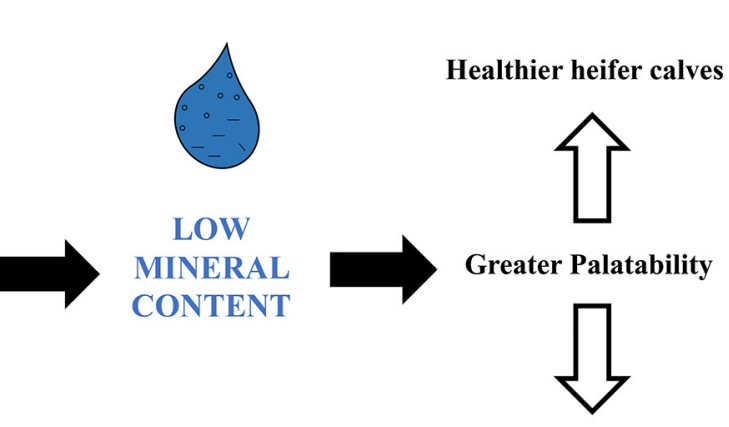

Encourage water intake

\section{Summary}

The purpose of this study was to assess the intake and preference of heifer calves for 3 types of drinking water: clean (tap water), well water, and water treated with a reverse osmosis (RO) purification system. The RO water purification system uses semipermeable membranes to remove larger mineral particles and some bacteria from drinking water. To determine water drinking preference, the consumption of each type of water by heifer calves was measured. Results demonstrated that heifers preferred to drink RO water over tap water or well water.

\section{Highlights}

- Heifer calves showed a preference among reverse osmosis water, municipal water, and untreated well water.

- Water quality affected water intake by heifer calves.

- Reverse osmosis water encouraged greater water intake by dairy heifers compared with municipal or untreated water.

- Reverse osmosis water would be an option where municipal water is not available.

\footnotetext{
'Dairy and Food Science Department, South Dakota State University, Brookings 57007, ${ }^{2}$ Department of Agriculture, Nutrition and Food Systems, University of New Hampshire, Durham 03824. *Corresponding author: maristela.rovai@sdstate.edu. @ 2021, The Authors. Published by Elsevier Inc. and Fass Inc. on behalf of the American Dairy Science Association ${ }^{\circledR}$. This is an open access article under the CC BY license (http://creativecommons.org/licenses/by/4.0/). Received March 05, 2021. Accepted July 07, 2021.
} 


\title{
Evaluation of the effects of water quality on drinking preferences of heifer calves
}

\author{
N. D. Senevirathne, ${ }^{1} \oplus$ J. L. Anderson, ${ }^{1} \odot$ P. S. Erickson, ${ }^{2} \odot$ and M. Rovai ${ }^{1 *} \odot$
}

Abstract: Drinking water quality requirements focus mainly on removing hazardous substances from the water supply, making it safe to drink and appropriate for livestock use. However, there is a concern that high mineral content in water may affect the drinking behavior of heifer calves, which may affect health and performance. In South Dakota, the primary water sources for agricultural use are surface or groundwater. Water quality varies between different regions of the state; in the eastern part of the state, the water is classified as "hard water" and calcium is the primary mineral found in the water. Our objective was to determine the water intake and drinking preference of heifer calves offered water treated with a reverse osmosis system (ROW), water treated by a municipal city water treatment plant (TW), and local untreated well water (UWW). Six Holstein heifer calves (100 $\pm 6.5 \mathrm{~d}$ of age; $137 \pm 5.9 \mathrm{~kg}$ of body weight) were used in a sequential elimination study. The calves were kept in individual pens $(1.5 \times 3 \mathrm{~m})$ and fed similar pellet and grass hay rations. Three troughs $(14 \mathrm{~L})$ of water were provided for each heifer calf and refreshed 3 times per day. Three water types were randomly assigned to the troughs, and an extra trough on each side was left empty to avoid preferential behavior by location. Throughout the 8-d experiment period, the intake of each type of water by each calf was measured. During the study adaptation phase, heifer calves were given TW for $3 \mathrm{~d}$ to establish baseline intake. During phase 1, all 3 water types were offered for $3 \mathrm{~d}$. The most-consumed water of each heifer calf was removed after intake data were collected. During phase 2, the remaining 2 water types were offered for $2 \mathrm{~d}$. Water preference ranking by heifer calf was determined based on intake amounts. Kendall's coefficient of concordance (W) was calculated to evaluate the agreement of preference among the heifer calves. The total average water intake was $16.0 \pm 2.14,15.8 \pm 1.95$, and $14.9 \pm 2.21 \mathrm{~kg} / \mathrm{d}$ for the adaptation phase, phase 1, and phase 2, respectively. During phase 1, average intake was $7.10 \pm 3.97,5.10 \pm 3.59$, and $3.55 \pm 4.89 \mathrm{~kg} / \mathrm{d}$ for ROW, TW, and UWW, respectively. Three heifer calves preferred ROW first and TW second. Two heifer calves selected TW first and ROW second. One heifer calf chose UWW first and was a potential outlier in the group for taste preference. Average preference rankings were $1.67,1.83$, and 2.50 for ROW, TW, and UWW, with lower numbers indicating greater preference. Overall, most of the heifer calves in the trial showed similar preferences $(\mathrm{W}=0.53)$, meaning that when one heifer calf had a preference for a particular water type, there was a trend for all the calves to prefer that water type. Results showed that the calves slightly preferred ROW over TW, and preferred both ROW and TW over UWW, with greater consumption of ROW when all 3 water types were offered.

G ood health and growth performance are essential aspects of the management of heifer calves. Poor water quality can negatively affect palatability and consumption of water by livestock, leading to compromised health and overall performance (NRC, 2001). Heifer calves are some of the most selective and vulnerable animals on the dairy farm when it comes to water palatability and health issues (Kertz et al., 1984). For heifer calves with developing immune and digestive systems, water intake has an enormous effect on calf growth performance (Kertz et al., 1984; Gottardo et al., 2002), rumen development, early starter intake (Appleman and Owen 1975), and nutrient utilization (NRC, 2001).

Water quality varies in different regions depending upon factors such as organoleptic properties (e.g., odor, taste, color), physicochemical substances (e.g., pH, total dissolved solids, hardness), and purification treatment processes (Beede, 1993). A high concentration of total solids, tastes, or odors in water can be readily detectable by animals, causing a decrease in water consumption. Therefore, water purification systems play an important role in encouraging water consumption. Local city water treatment centers usually treat municipal water for macro- and microminerals and microbial contaminants. Reverse osmosis purification technology is another possible purification system which is widely used in the United States. Reverse osmosis processing involves using a semipermeable membrane to remove larger particles in water, including some minerals and other impurities such as iron and microorganisms, to produce reverse osmosis drinking water (ROW).

However, many farmers commonly use untreated groundwater from onsite private wells. The untreated well water (UWW) commonly found in eastern South Dakota is considered hard water, containing a high concentration of minerals (i.e., calcium and magnesium) compared with both municipal city water (TW) and ROW. Iron, manganese, and aluminum also contribute to water hardness in this region (Patience, 1994; Morgan, 2011). Dairy farmers commonly use TW or UWW depending on availability at their location. In South Dakota, the most common water is TW, which is considered hard water with greater concentrations of several minerals and total dissolved solids (TDS) compared with ROW.

The effects of water source or treatment on drinking water preference and intake of heifer calves have rarely been studied, to our knowledge. Therefore, the objectives of this study were to determine how water quality affects water intake by heifer calves and whether they show a preference for one type of water. We

\footnotetext{
'Dairy and Food Science Department, South Dakota State University, Brookings 57007, ${ }^{2}$ Department of Agriculture, Nutrition and Food Systems, University of New Hampshire, Durham 03824. *Corresponding author: maristela.rovai@sdstate.edu. @ 2021, The Authors. Published by Elsevier Inc. and Fass Inc. on behalf of the American Dairy Science Association ${ }^{\circledR}$. This is an open access article under the CC BY license (http://creativecommons.org/licenses/by/4.0/). Received March 05, 2021. Accepted July 07, 2021.
} 
hypothesized that improved water quality using a reverse osmosisfiltered system would increase overall intake by heifer calves, and that heifer calves would prefer this water compared with TW and UWW.

All animal use protocols were approved by the South Dakota State University Institutional Animal Care and Use Committee, and the study was conducted at the South Dakota State University Dairy Research and Training Facility (Brookings, SD). Six weaned Holstein heifer calves (approximately $100 \pm 6.5 \mathrm{~d}$ old, $137 \pm 5.9$ $\mathrm{kg}$ of BW) were used in an unblinded sequential elimination study (Nombekela et al., 1994; Erickson et al., 2012) to determine the palatability or heifer calf preference for different water types. Experiment sample size was determined according to Nombekela et al. (1994) and Erickson et al. (2012). No animals were excluded during the study. Three water sources were tested: (1) purified reverse osmosis water (ROW), (2) municipal city tap water (TW), and (3) untreated well water (UWW).

The ROW water purification system was provided by Culligan Water Filtration Systems (Culligan International Co.), and tap water was treated by the local municipal city water treatment center (Brookings, SD). Untreated well water was obtained from a local dairy farm.

Heifer calves were kept in individual pens $(150 \times 300 \mathrm{~cm})$ and bedded with dried wood shavings. All 6 pens were inside a building for protection from the environment. The heifer calves were fed grass hay ad libitum and grower pellets (Hubbard Feed) twice per day, with $2.27 \mathrm{~kg}$ of pellets offered each time. Five similar troughs (Springer Magrath) for water were provided along the long side of each pen. Each trough was $26.5 \mathrm{~cm}$ wide, $27.5 \mathrm{~cm}$ long, and $27.5 \mathrm{~cm}$ deep, and could hold up to $14 \mathrm{~L}$ of water. An empty trough was included on each end to nullify border effects. Before trial initiation, heifer calves drank TW because it was the drinking water source regularly used at the Dairy Research and Training Facility. Heifer calves were given a 3-d adaptation period to the pens, water troughs, and feeding methods. During this adaptation period, TW was offered in all 3 test troughs to establish baseline intakes. Phase 1 lasted $3 \mathrm{~d}$, in which heifer calves were offered all 3 water types. After $3 \mathrm{~d}$, the most-consumed water type of each heifer calf was removed, and for $2 \mathrm{~d}$, they were offered the remaining 2 types of water ad libitum. Water and feed were offered and weighed at $0900 \mathrm{~h}$ each day.

The grower pellets were from a commercial source and of proprietary ingredient composition. The analyzed DM, CP, and starch contents of grower pellets were $89.04,18.63$, and $21.25 \%$ on a DM basis, respectively. The measured DM, CP, and NDF contents of grass hay were $84.44,6.98$, and $61.10 \%$ on a DM basis, respectively. The hay and grower pellets were the regular herd diet for heifer calves of this age range at the Dairy Research and Training Facility (Brookings, SD) at the time of the study.

Water levels in each trough were checked and more was added as necessary at 0600,1400 , and $1800 \mathrm{~h}$ to ensure ad libitum intakes. The second daily feeding of pellets was at $1800 \mathrm{~h}$. Daily intakes of all water types were recorded by weight $(\mathrm{kg} / \mathrm{d})$. Each day, the position of the trough of each water offered was randomized for each heifer calf so that the location of the trough did not influence preference. Three samples of each water type were collected during the test period for compositional analysis. The composition of the water sources was analyzed by DairyLand Laboratories (Arcadia,
WI). All analytical methods are from APHA (1992). Water nitrate composition was analyzed using the nitrate electrode method (4500NO3-D; APHA, 1992, pp 4-88). The mineral composition, including sulfates, $\mathrm{Ca}, \mathrm{Mg}, \mathrm{Cu}, \mathrm{Fe}, \mathrm{Zn}, \mathrm{Na}, \mathrm{Mn}, \mathrm{P}$, and $\mathrm{K}$, was analyzed using the inductively coupled plasma (ICP) method (3120 B; APHA, 1992, pp 3-34). Chloride was analyzed using the potentiometric method (4500 $\mathrm{Cl}^{-}$; APHA, 1992, pp 4-51). Water $\mathrm{pH}$ was analyzed using the electrometric method (4500-H B; APHA, 1992, pp 4-65). The presence of coliforms was determined using the chromogenic substrate test (9223 B; APHA, 1992, pp 9-65). Total dissolved solids were measured using a gravimetric method and dried at $180^{\circ} \mathrm{C}$ until there was no change in dish weight $(2540 \mathrm{C}$; APHA, 1992, pp 3-55).

Pellets and hay composites were dried in duplicate for $48 \mathrm{~h}$ at $55^{\circ} \mathrm{C}$ in a Despatch oven (style V-23, Despatch Oven Co.). Dried samples were ground to 2-mm particle size using a Wiley mill (model 3; Arthur H. Thomas Co.) and then ground to 1-mm particle size using an ultracentrifuge mill (Brinkman Instruments Co.). To correct analyses to $100 \% \mathrm{DM}, 1$-g aliquots of samples were dried for $3 \mathrm{~h}$ in a $105^{\circ} \mathrm{C}$ oven. Grass hay samples and pelleted starter samples were analyzed for nitrogen content by the Dumas combustion method (AOAC International, 2002; method 968.06), on a Rapid N cube (Elementar Analysensysteme GmBH). To determine $\mathrm{CP}$ concentrations, feed sample nitrogen content was multiplied by 6.25. Neutral detergent fiber (Van Soest et al., 1991) was analyzed using the Ankom 200 fiber analysis system (Ankom Technology Corp.). Heat-stable $\alpha$-amylase and sodium sulfite were used for NDF analysis. Starch concentration was determined using a modified glucose analysis method (Bach Knudsen, 1997) completed on a YSI 2700 Select Biochemistry Analyzer (YSI Inc.).

The heifer calves were weighed and measured for hip and withers height at the start and end of the study to characterize body size. Additionally, BCS on a scale of 1 (emaciated) through 5 (obese) was recorded, and ADG was calculated.

Water preference was analyzed by assigning a rank for most preferred based on water consumption from each source. Rankings were determined by giving a score of 1 for the most preferred water and a score of 3 for the least preferred water each day. Consumed water intakes during phases 1 and 2 were considered for rankings. Data were analyzed using SAS procedures (version 9.3; SAS Institute Inc.). Means and standard errors (SE) were generated using PROC MEANS for chemical composition, water intake data, BW, hip height, withers height, BCS, and ADG. The $\chi^{2}$ distribution was used for analysis of probability values. Agreement of water drinking preference ranking among heifer calves was calculated using Kendall's coefficient of concordance $(\mathbf{W})$, where $\mathrm{W}=k(k-1) / 2$, and $k=$ the number of heifer calves (Nombekela et al., 1994).

Table 1 presents the chemical composition of ROW, TW, and UWW sources. Significant differences were found among $\mathrm{Ca}, \mathrm{Mg}$, $\mathrm{K}, \mathrm{Na}, \mathrm{Cl}$, and sulfate contents. These differences are explained by the ROW system, which corresponds to more purified water due to the semipermeable membrane used. The sulfate content was much lower in ROW compared with TW and UWW. Concentrations of sulfate $>1,000 \mathrm{mg} / \mathrm{L}$ have been shown to cause severe problems in cattle, such as decreased feed and water intake (Weeth and Hunter, 1971). Also, the combination of $\mathrm{Mg}$ and $\mathrm{Na}$ may increase the severity of these problems (Weeth and Hunter, 1971). Increased iron consumption through water or feed may be associated with 
Table 1. Chemical composition of reverse osmosis water (ROW), municipal city tap water (TW), and untreated well water (UWW)

\begin{tabular}{|c|c|c|c|c|c|}
\hline \multirow[b]{2}{*}{ Item } & \multicolumn{3}{|c|}{ Water type } & \multirow[b]{2}{*}{ SEM } & \multirow[b]{2}{*}{$P$-value } \\
\hline & ROW & TW & UWW & & \\
\hline No. of samples & 3 & 3 & 3 & & \\
\hline Nitrate-N, mg/L & 1.21 & 1.46 & 1.19 & 0.30 & 0.25 \\
\hline $\mathrm{pH}$ & 7.35 & 8.23 & 7.66 & 0.90 & 0.11 \\
\hline Calcium, mg/L & $5.33^{\mathrm{a}}$ & $40.00^{b}$ & $230.00^{c}$ & 6.61 & $<0.001$ \\
\hline Magnesium, mg/L & $1.07^{\mathrm{a}}$ & $36.20^{\mathrm{b}}$ & $94.30^{c}$ & 6.55 & $<0.001$ \\
\hline Phosphorus, mg/L & $0.07^{\mathrm{a}}$ & $0.36^{b}$ & $0.06^{a}$ & 0.20 & 0.01 \\
\hline Potassium, mg/L & $0.23^{\mathrm{a}}$ & $3.34^{b}$ & $8.22^{c}$ & 0.29 & $<0.001$ \\
\hline Copper, mg/L & 0.01 & 0.01 & 0.02 & 0.11 & 0.52 \\
\hline Iron, mg/L & $0.04^{\mathrm{a}}$ & $0.17^{b}$ & $0.25^{b}$ & 0.01 & 0.001 \\
\hline Zinc, mg/L & 0.02 & 0.02 & 0.02 & 0.03 & 0.97 \\
\hline Sodium, mg/L & $2.50^{\mathrm{a}}$ & $19.10^{b}$ & $73.90^{c}$ & 1.00 & $<0.001$ \\
\hline Manganese, mg/L & $0.002^{\mathrm{a}}$ & $0.01^{\mathrm{a}}$ & $0.23^{b}$ & 0.01 & $<0.001$ \\
\hline Chloride, $\mathrm{mg} / \mathrm{L}$ & $5.20^{\mathrm{a}}$ & $24.20^{b}$ & $6.67^{a}$ & 3.10 & $<0.001$ \\
\hline Sulfates, $\mathrm{mg} / \mathrm{L}$ & $1.36^{\mathrm{a}}$ & $195.00^{\mathrm{b}}$ & $622.00^{c}$ & 51.00 & $<0.001$ \\
\hline Total dissolved solids, ${ }^{1} \mathrm{mg} / \mathrm{L}$ & $339.00^{\mathrm{a}}$ & $462.00^{\mathrm{b}}$ & $1,432.00^{c}$ & 82.70 & $<0.001$ \\
\hline Water hardness, mg/L & 17.60 & 249.00 & 964.00 & 43.60 & $<0.001$ \\
\hline Escherichia coli, cfu/mL & $\mathrm{ND}^{2}$ & ND & $1,200.00$ & - & - \\
\hline
\end{tabular}

${ }^{a-c}$ Values with different lowercase superscripts within a row differ significantly.

${ }^{1}$ Analyzed with gravimetric method.

${ }^{2}$ Not detected.

gastrointestinal symptoms, including diarrhea (Beede, 2005). Young calves and heifers are especially vulnerable to diarrhea and may become very dehydrated and metabolically imbalanced (Svensson et al., 2003; Beede, 2005). The concentration of TDS was significantly higher in UWW and TW than in ROW. Saline and sodium chloride $(\mathrm{NaCl})$ are the main factors that increase TDS concentration in water. In addition, greater concentrations of sulfate ions or calcium and magnesium salts can be responsible for large TDS values in water. Both TDS and $\mathrm{NaCl}$ concentration in drinking water may affect feed intake and total water consumption. Elevated TDS adversely affects water palatability, which influences water consumption, and indirectly affects feed consumption and performance. A TDS value $<3,000 \mathrm{mg} / \mathrm{L}$ is acceptable in drinking water and should not affect cattle but may cause diarrhea in young heifer calves (NRC, 2001). Hardness also plays a significant role in drinking behavior. Hardness is generally measured by $\mathrm{Ca}, \mathrm{Mg}$, and Fe concentrations in water. In the NRC (1974) guidelines, older cows were not affected by water hardness $<290 \mathrm{mg} / \mathrm{L}$ (measured as $\mathrm{Ca}$ and $\mathrm{Mg}$ concentrations). In this study, TW and UWW sources were harder than ROW, as expected. Nitrate-N concentration was comparable among water sources. Even small increases of nitrate$\mathrm{N}$ may influence the rumen's microbial ecosystem and cause digestive problems (NRC, 2001).

The mean BW of heifer calves in this study was $132.47 \pm 1.04$ $\mathrm{kg}$. Hip height averaged $103.75 \pm 7.79 \mathrm{~cm}$, and withers height averaged $99.84 \pm 0.26 \mathrm{~cm}$. The average BCS of all 6 heifer calves was $2.92 \pm 0.20$, and ADG was maintained at $1.02 \pm 0.06 \mathrm{~kg} / \mathrm{d}$ during the study. Overall, heifer calves were uniform for body size characteristics. Diarrhea and other clinical signs of disease were not observed throughout the study period.

The average DMI of grass hay was $1.23 \pm 0.19 \mathrm{~kg} / \mathrm{d}$ during phase 1 and $1.30 \pm 0.23 \mathrm{~kg} / \mathrm{d}$ during phase 2 . The average pellet DMI was $8.42 \pm 0.25 \mathrm{~kg} / \mathrm{d}$ during phase 1 and $8.59 \pm 0.56 \mathrm{~kg} / \mathrm{d}$ during phase 2. Mean feed DMI increased during the trial period,

Table 2. Total daily water intakes ( $\mathrm{kg} / \mathrm{d}$ ) by heifer calves and water intakes by each heifer calf of reverse osmosis water (ROW), municipal city tap water (TW), and untreated well water (UWW) in each phase

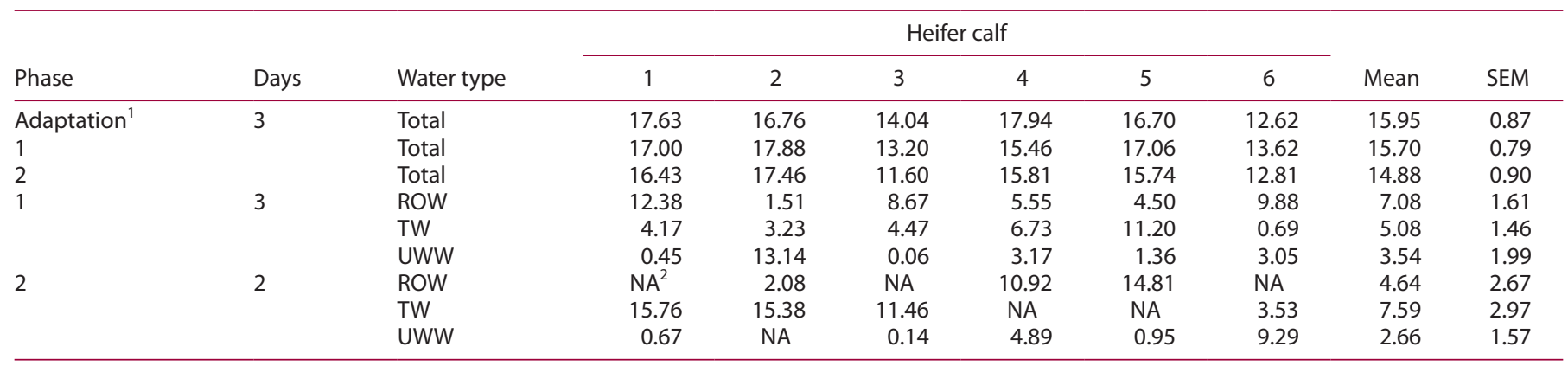

'During the adaptation period, calves were offered only the control municipal water.

${ }^{2} \mathrm{NA}=$ not available because the most preferred water type was removed in phase 2 . 
Table 3. Number of days that water type ${ }^{1}$ was preferred by each heifer calf and mean and by heifer calf preference ranking ${ }^{2}$ of each water source in phase 1

\begin{tabular}{|c|c|c|c|c|c|c|c|c|c|}
\hline \multirow[b]{2}{*}{ Item } & \multirow{2}{*}{$\begin{array}{l}\text { Water } \\
\text { type }\end{array}$} & \multicolumn{6}{|c|}{ Heifer calf } & \multirow{2}{*}{$\begin{array}{l}\text { Total } \\
\text { days }\end{array}$} & \multirow{2}{*}{$\begin{array}{l}\text { Mean } \\
\text { ranking }\end{array}$} \\
\hline & & 1 & 2 & 3 & 4 & 5 & 6 & & \\
\hline \multirow[t]{3}{*}{ Days preferred } & ROW & 3 & 0 & 2 & 0 & 0 & 3 & 8 & \\
\hline & TW & 0 & 0 & 1 & 2 & 3 & 0 & 6 & \\
\hline & UWW & 0 & 3 & 0 & 1 & 0 & 0 & 4 & \\
\hline \multirow[t]{3}{*}{ Ranks $^{2}$} & ROW & 1 & 3 & 1 & 2 & 2 & 1 & & 1.67 \\
\hline & TW & 2 & 2 & 2 & 1 & 1 & 3 & & 1.83 \\
\hline & UWW & 3 & 1 & 3 & 3 & 3 & 2 & & 2.50 \\
\hline
\end{tabular}

${ }^{1}$ ROW $=$ reverse osmosis water, $\mathrm{TW}=$ municipal city tap water, $\mathrm{UWW}=$ untreated well water.

${ }^{2} \mathrm{~A}$ lower number indicates greater preference.

as expected for growing heifer calves (Chapman et al., 2016). The different water sources offered did not appear to influence feed intake in this short-term study.

Table 2 shows the total water consumption of each heifer calf during each phase of the study. Water intakes were consistent during the adaptation period and phase 1 for all animals $( \pm 0.25 \mathrm{~kg} / \mathrm{d}$ water intake). In phase 2, after the preferred water was removed, there was an average decrease of $0.82 \mathrm{~kg} / \mathrm{d}$ in water consumption by each heifer. The observed decrease in water consumption can be related to the organoleptic (i.e., odor, taste) and physicochemical (i.e., $\mathrm{pH}$, TDS, hardness) changes in the remaining water types. These changes in quality factors are easily perceived by animals and can depress water consumption (Beede, 1993).

In other research, Holstein heifer calves showed an increased preference for drinking water when salinity approached 2,000 ppm and a decrease when salinity was greater than 2,500 ppm (Wegner and Schuh, 1974). In contrast to our water consumption findings, other authors reported, in a preferential feed study, that average daily DMI was not affected when the most preferred feed was removed (Erickson et al., 2012). Chapman et al. (2016) reported that DMI was not affected by removing the most preferred diet in a preference study of essential oil (cinnamaldehyde) inclusion rates. Mean and total water intakes by each water source are shown in Table 2. During phase 1, ROW intake was the highest among the 3 water treatments. The mean intake of ROW was $7.08 \pm 1.61 \mathrm{~kg} / \mathrm{d}$. The second preference was TW, with a mean intake of $5.08 \pm 1.46$ $\mathrm{kg} / \mathrm{d}$. The last preference was UWW, with a mean intake of 3.54 $\pm 1.99 \mathrm{~kg} / \mathrm{d}$. During the second phase, the most preferred water was removed from each heifer calf, which skewed the mean daily intake of each type. The purpose of phase 2 was to establish the ranking of second and third preferences.

Table 3 shows the number of days in phase 1 that heifer calves consumed the most of a particular water type. Most heifer calves chose the same water source for all $3 \mathrm{~d}$. Heifer calf 3 chose TW on $\mathrm{d} 1$ of the period and then chose ROW on $\mathrm{d} 2$ and 3 . It is possible that this calf chose TW on $\mathrm{d} 1$ due to preconditioning, but this is speculation. Heifer calf 4 chose TW for $2 \mathrm{~d}$ and UWW for $1 \mathrm{~d}$.

The overall ranking for a water source preference is also presented in Table 3. Results demonstrated that heifer calves preferred ROW, although TW was a close second. Untreated well water was preferred less than ROW or TW. Heifer calf 2 was the only one that preferred UWW out of all 6 heifer calves. The other 5 heifer calves preferred ROW over UWW (W=0.53; $P=0.07)$. Overall, $\mathrm{W}=$ 0.19 for agreement of preference among heifer calves $(P=0.31)$.
These results show a tendency to choose ROW over the other water types. Increasing the number of heifer calves in future studies may improve the Kendall's coefficient of concordance.

These results demonstrated that the amount of TDS and hardness of the water source influence taste preferences and drinking behavior of growing heifer calves. Although feed quality is important, water quality and consumption are essential for livestock performance but often overlooked. Water intake may affect rumen function and lead to reduced feed intake and utilization. Water intake is also important for animals tolerating warm weather and environmental stress. Cattle should be offered good-quality, fresh, clean water that is changed often; just because a water tank is available, does not ensure that the water is consumed.

In agreement with our hypothesis, heifer calves most preferred ROW, with TW a close second, and least preferred UWW. These findings are attributed to improvements in physicochemical and organoleptic quality of water from the reverse osmosis filtration system and the municipal water treatment system compared with well water. It should be noted that as the heifer calves were typically given and adapted to TW, they may have biased taste preference toward TW and increased sensitivity to the differences between ROW and TW. There was a clear preference by 5 out of 6 heifer calves to prefer ROW over UWW. Therefore, in situations where groundwater or well water is the only water source, a reverse osmosis filtration system may encourage greater water intake by growing heifer calves.

\section{References}

AOAC International. 2002. Official Methods of Analysis. 17th ed. AOAC International.

APHA (American Public Health Association). 1992. Standard method for the examination of water and wastewater. 18th ed. APHA.

Appleman, R. D., and F. G. Owen. 1975. Recent advances in calf rearing: Breeding, housing, and feeding management. J. Dairy Sci. 58:447-464. https://doi.org/10.3168/jds.S0022-0302(75)84588-7.

Bach Knudsen, K. E. 1997. Carbohydrate and lignin contents of plant materials used in animal feeding. Anim. Feed Sci. Technol. 67:319-338. https://doi .org/10.1016/S0377-8401(97)00009-6.

Beede, D. K. 1993. Water Nutrition and Quality For Dairy Cattle. Page 193 in Proc. Western Large Herd Management Conference, Las Vegas, NV.

Beede, D. K. 2005. Assessment of water quality and nutrition for dairy cattle. Mid-South Ruminant Nutrition Conference, Arlington, TX. Texas Animal Nutrition Council, Champaign, IL.

Chapman, C. E., R. G. Cabral, K. M. Aragona, and P. S. Erickson. 2016. Short communication: Cinnamaldehyde taste preferences of weaned dairy heifers. J. Dairy Sci. 99:3607-3611. https://doi.org/10.3168/jds.2015-10582. 
Erickson, P. S., S. P. Marston, M. Gemmel, J. Deming, R. G. Cabral, M. R. Murphy, and J. I. Marden. 2012. Short communication: Kelp taste preferences by dairy calves. J. Dairy Sci. 95:856-858. https://doi.org/10.3168/ jds.2011-4826.

Gottardo, F., S. Mattiello, G. Cozzi, E. Canali, E. Scanziani, L. Ravarotto, V. Ferrante, M. Verga, and I. Andrighetto. 2002. The provision of drinking water to veal calves for welfare purposes. J. Anim. Sci. 80:2362-2372. https://doi.org/10.2527/2002.8092362x.

Kertz, A. F., L. F. Reutzel, and J. H. Mahoney. 1984. Ad libitum water intake by neonatal calves and its relationship to calf starter intake, weight gain, feces score and season. J. Dairy Sci. 67:2964-2969. https://doi.org/10.3168/jds .S0022-0302(84)81660-4.

Morgan, S. 2011. Water quality for cattle. Page 285-295 in Ruminant Toxicology, An Issue of Veterinary Clinics: Food Animal Practice. Volume 27, Issue 2 of The Clinics: Veterinary Medicine. G. Osweiler, ed. Elsevier Health Sciences.

NRC. 1974. Nutrients and Toxic Substances in Water for Livestock and Poultry. National Academies Press.

NRC. 2001. Nutrient Requirements of Dairy Cattle. 7th rev. ed. National Academies Press.

Nombekela, S. W., M. R. Murphy, H. W. Gonyou, and J. I. Marden. 1994. Dietary preferences in early lactation cows as affected by primary tastes and some common feed flavors. J. Dairy Sci. 77:2393-2399. https://doi.org/10 $.3168 /$ jds.S0022-0302(94)77182-4.

Patience, J. F. 1994. Water quality and quantity: Importance in animal and poultry production. Biotechnology in the Feed Industry. Proc. Alltech's 5th Annual Symposium. 204:121-138.
Svensson, C., K. Lundborg, U. Emanuelson, and S. O. Olsson. 2003. Morbidity in Swedish dairy calves from birth to 90 days of age and individual calflevel risk factors for infectious diseases. Prev. Vet. Med. 58:179-197. https: //doi.org/10.1016/S0167-5877(03)00046-1.

Van Soest, P. J., J. B. Robertson, and B. A. Lewis. 1991. Methods for dietary fiber, neutral detergent fiber, and non-starch polysaccharides in relation to animal nutrition. J. Dairy Sci. 74:3583-3597. https://doi.org/10.3168/jds S0022-0302(91)78551-2.

Weeth, H. J., and L. H. Hunter. 1971. Drinking of sulfate water by cattle. J. Anim. Sci. 32:277-281. https://doi.org/10.2527/jas1971.322277x.

Wegner, T. N., and J. D. Schuh. 1974. Effect of highly mineralized livestock water supply on water consumption and blood and urine electrolyte profiles in dairy cows. J. Dairy Sci. 57:608. (Abstr.)

\section{Notes}

N. D. Senevirathne $\odot$ https://orcid.org/0000-0002-5676-4785

J. L. Anderson ๑ https://orcid.org/0000-0001-7590-0749

P. S. Erickson ๑ https://orcid.org/0000-0002-8028-3279

M. Rovai ๑ https://orcid.org/0000-0001-9201-1505

This research was funded by Culligan Water (Brookings, SD) with support from the South Dakota State University Agricultural Experiment Station.

The authors have not stated any conflicts of interest. 